\title{
Formulation and Characterization of Fast Dissolving Tablets Using Salvia Hispanica (Chia Seed) Mucilage as Superdisintegrant
}

\author{
Reecha Madaan $^{1^{*}}$, Rajni Bala ${ }^{1}$, Simran Kaur Zandu ${ }^{1}$, Inderbir Singh ${ }^{1}$ \\ 1 Chitkara University, Chikara College of Pharmacy, Rajpura, Punjab, India
}

\begin{abstract}
Gums and mucilage are mainly explored for its various applications in dosage form development. Salvia hispanica (Lamiaceae) i.e. Chia seed mucilage mainly composed of xylose, glucose and methyl glucuronic acid that forms a branched polysaccharide of high molecular weight. The present study strives to investigate the disintegration ability of Salvia hispanica mucilage in the formulation of fast dissolving tablets of selected model drug indomethacin. Indomethacin belonging to the category of NSAIDs and is used as a therapeutic agent for relieving pain, inflammation and joint stiffness. Salvia hispanica mucilage was isolated and characterized by physicochemical parameters. Indomethacin tablets (F1-F5) were formulated by direct compression method using $S$. hispanica mucilage powder in varying concentration range of $2 \%, 4 \%, 6 \%, 8 \%$ and $10 \%$ respectively. Crospovidone (6\%) was used as synthetic disintegrating agent for comparison. Micro crystalline cellulose was used as tablet diluent, mannitol, talc and magnesium stearate were used to enhance mouth feel and as lubricants respectively. All the formulations were evaluated for their pre and post compression parameters like tablet hardness, thickness, $\%$ friability, wetting time, drug content, disintegration time which was found to be in permissible limits. Drug excipient compatibility study was carried out using FTIR technique. The formulation $\mathrm{F}_{3}$ containing $6 \%$ of Salvia hispanica mucilage exhibit maximum drug release of $98.5 \%$ in 30 minutes, $\mathrm{F}_{4}$ and $\mathrm{F}_{5}$ formulations containing $8 \%$ and $10 \%$ of Salvia hispanica mucilage showed $82.4 \%$ and $80.5 \%$ drug release in 30 minutes. Results of in vitro drug released kinetic study indicated that the optimized formulation $\mathrm{F}_{3}$ followed Korsmeyer Peppas model with $\mathrm{R}^{2}$ value of 0.9793 . Stability studies performed on $\mathrm{F}_{3}$ formulation indicated that the prepared tablets remain stable for the period of 90 days and showed no change
\end{abstract}

\footnotetext{
${ }^{\star}$ Corresponding Author: Reecha Madaan, e-mail: reecha.madan@chitkara.edu.in Reecha Madaan ORCID Number: 0000-0002-4362-0272

Rajni Bala ORCID Number: 0000-0002-6960-3403

Simran Kaur Zandu ORCID Number: 0000-0002-6764-2329

Inderbir Singh ORCID Number: 0000-0002-1860-4246

(Received 09 September 2019, accepted 05 November 2019)
} 
in in vitro drug release pattern. Various investigations have demonstrated that the $S$. hispanica seed mucilage can be successfully used as a natural superdisintegrant which is comparable to various synthetic disintegrants used in the formulation of fast dissolving drug delivery systems.

Keywords: Indomethacin, chia seed mucilage, Salvia hispanica, superdisintegrant, fast dissolving tablets

\section{INTRODUCTION}

Oral administration is the most familiar and preferential route for the delivery of therapeutic agents to the patients. ${ }^{1}$ Mainly, tablets are medications of choice for patients because of dose precision, self-medication, avoidance of fear of needles, economical therapy, compactness, easy administration and patient compliance. No requirement for the maintenance of sterile conditions is there, therefore manufacturing cost is low. ${ }^{2}$ Tablet formulations include the therapeutic active component i.e., active pharmaceutical ingredient (API) and the excipients which are the pharmaceutically inactive components. Regardless of their inactivity, excipients possess specific functionalities affecting the biopharmaceutical action of the formulation. The excipients incorporated into the tablet formulations are binders, diluents, disintegrants, lubricants, preservatives, colorants and flavoring agents. ${ }^{3}$ Disintegration of the tablet is the important step involved in the release of the drug, therefore, the most essential excipient amidst all is the disintegrant which is responsible for the breaking up of the dosage form into smaller particles after it has been ingested and further allowing the dissolution and ultimately the absorption of the drug. ${ }^{4}$ The disintegrant property can be modified for the development of fast dissolving/disintegrating tablets (FDT) which are beneficial for paediatric, geriatric, dysphagic, bedridden and uncooperative patients as conventional tablets might pose a difficulty in swallowing because of coughing, motion sickness, abrupt episodes of allergic attack or in case of unavailability of water. FDTs are novel dosage form which utilizes superdisintegrants for immediate and complete disintegration of the tablet, generally within the range of a few seconds to less than a minute, when placed on the tongue, thereby leading to drug release in the saliva. They are also known as 'quick-dissolving', 'orodispersible', 'melt-in-mouth' or 'mouth-dissolving tablets'. ${ }^{5}$ Diverse factors influencing the disintegration process of the tablet include the particle size, moisture content, compression force, type and properties of the disintegrant, tablet hardness, nature of the drug, compatibility with other ingredients and the process of addition as well as mixing. ${ }^{6,7}$ The crucial mechanisms involved in the tablet disintegration process include swelling, deformation, wicking, enzymatic reactions and repulsions between the particles. ${ }^{8}$ 
Different categories of superdisintegrants include natural (like Gums and mucilage) and synthetic superdisintegrants (croscarmellose sodium, crospovidone, carmellose, sodium starch glycollate etc.). Various Gums and mucilage such as Mangifera indica gum, Locust Bean gum, Fenugreek seed mucilage, Ficus indica fruit mucilage, Lepidium sativum mucilage, etc. have been utilized as superdisintegrant in the formulation of FDT. Additional advantages of natural polymers include easy accessibility, biocompatibility and lower cost as compared to synthetic ones. ${ }^{9}$

Chia seeds are obtained from Salvia hispanica, a herbaceous plant belonging to the family Lamiaceae. It is a consumable seed having remarkable therapeutic effects as well as nutritional value due to the presence of high quality carbohydrate (41\%), fat (30-33\%), protein (15-25\%) and dietary fibre (18-30\%) and mucilage. It is an excellent source of omega-3 fatty acid, antioxidants as well as various polyphenolic compounds such as caffeic acid, quercetin, chlorogenic acid, kaempferol and myricetin. ${ }^{10}$

The polysaccharides that make up the mucilage network of chia seeds are located in the outer seed coat layers and are composed of $\beta$-D-xylopyranosyl, $\alpha$-D-glucopyranosyl and 4-O-methyl- $\alpha$-D-glucopyranosyluronic acid. Upon addition of water the polysaccharides exudate, absorb water and unravel to full extension. Chia seeds i.e. Salvia hispanica mucilage gels can be used as pharmaceutical excipients in drug delivery. ${ }^{11}$

The present study strives to investigate the disintegration ability of Salvia hispanica mucilage in the formulation of FDT of the selected model drug Indomethacin. Indomethacin belongs to NSAID and is used as a therapeutic agent for relieving pain, inflammation and joint stiffness. The drug is included in BCS class II drug (poorly aqueous soluble and highly permeable), so it is worth to develop FDT of Indomethacin to enhance its solubility and bioavailability.

\section{METHODOLOGY}

\section{Materials}

Salvia hispanica seeds were procured from the local market of Patiala and authentication of the sample was confirmed from Department of Pharmacognosy, Chitkara University Punjab. Indomethacin was obtained as gift sample from Triko Pharmaceutical Rohtak. Crospovidone, Microcrystalline cellulose, Mannitol, magnesium stearate was purchased from Loba Chemie Ltd. Mumbai, India.

\section{Isolation of mucilage}

The seeds of Salvia hispanica were soaked in water for overnight (seed-solvent ratio was 1:20), boiled for half an hour and mixed on magnetic stirrer for 1 hour 
so that the mucilage releases completely into water. The resulting mixture was centrifuged at 5000 rpm for $50 \mathrm{~min}$, after which three different layers were formed. ${ }^{11}$ Only the gel layer was collected and dried in a hot air oven at $50^{\circ} \mathrm{C}$. The product was grounded, passed through the sieve no. 80 and then stored at room temperature in desiccators for further use.

\section{Physicochemical evaluation of mucilage}

Isolated mucilage was evaluated for various physicochemical properties. ${ }^{12}$

\section{Drug excipient compatibility studies}

Drug excipient compatibility studies were performed with the help of Fourier transforms infrared (FTIR) spectroscopy. FTIR spectra (range of 3500-500 $\mathrm{cm}^{-1}$ ) of the Indomethacin, Salvia hispanica mucilage and combined mixture of both (1:1) were taken (Bruker Alpha T).

\section{Standard calibration curve of Indomethacin}

For preparing the standard calibration curve of Indomethacin, $100 \mathrm{mg}$ drug was weighed and transferred to $100 \mathrm{ml}$ of volumetric flask. The drug was dissolved in $100 \mathrm{ml}$ of phosphate buffer pH 6.8 (stock I). $10 \mathrm{ml}$ solution was withdrawn from stock I and diluted upto $100 \mathrm{ml}$ with phosphate buffer $\mathrm{pH}$ 6.8(stock II). Different dilutions were prepared by pipetting out o.2, 0.4, o.6, o.8, 1 and $2 \mathrm{ml}$ from stock solution II and then finally adjusting the volume upto $10 \mathrm{ml}$. The absorbance of all the resulting solutions was measured at 325 $\mathrm{nm}$ with the help of UV-VS spectrophotometer (Systronics). ${ }^{13}$

\section{Formulation of Fast Dissolving Tablets of Indomethacin using Sal- via hispanica mucilage}

Fast dissolving tablets of Indomethacin (F1-F6) were prepared by direct compression method. The mucilage of Salvia hispanica was used in varying concentrations such as $2 \%, 4 \%, 6 \%, 8 \%$ and $10 \%$ as superdisintegrant. Microcrystalline cellulose was used as diluent, mannitol as filler, talc as glidant and magnesium stearate as lubricant. All the constituents were weighed according to the composition given in Table 1, sifted through mesh \# 60 and mixed thoroughly in ascending order. The formulated blend was then examined for its pre-compression parameters. These formulations were compared with the standard formulation F6 containing crospovidone as superdisintegrant. 
Table 1. Composition of fast dissolving tablets of Indomethacin.

\begin{tabular}{|c|c|c|c|c|c|c|}
\hline Ingredients (mg) & \multicolumn{5}{|c|}{ Formulation batches } \\
\hline & F1 & F2 & F3 & F4 & F5 & F6 \\
\hline Indomethacin & 150 & 150 & 150 & 150 & 150 & 150 \\
\hline Salvia hispanica mucilage & $2 \%$ & $4 \%$ & $6 \%$ & $8 \%$ & $10 \%$ & - \\
\hline Crospovidone & - & - & - & - & - & $6 \%$ \\
\hline MCc 102 & 112 & 106 & 100 & 94 & 88 & 82 \\
\hline Mannitol & 25 & 25 & 25 & 25 & 25 & 25 \\
\hline Talc & 2 & 2 & 2 & 2 & 2 & 2 \\
\hline Magnesium Stearate & 5 & 5 & 5 & 5 & 5 & 5 \\
\hline Total & 300 & 300 & 300 & 300 & 300 & 300 \\
\hline
\end{tabular}

\section{Pre compression parameters}

The different powder blends were evaluated for pre compression parameters by finding the bulk density, tapped density, Carr's index, Angle of repose and Hausner ratio according to methods specified in pharmacopoeia. ${ }^{14}$

\section{Evaluation of tablets}

The prepared tablets were characterized for different post compression parameters such as weight variation, hardness, \% friability, thickness, wetting time, drug content and disintegration time. The hardness of the tablets was assessed with the help of Monsanto hardness tester. It was done by taking the average value of any three tablets from every batch. Friability was tested by taking 20 tablets and placing the weighed tablets in the friability chamber (Roche friability tester) for 4 $\mathrm{min}$ at $25 \pm 1 \mathrm{rpm}$, and then percentage of the weight loss was determined. Disintegration test was performed in phosphate buffer of $\mathrm{pH} 6.8$ at $37 \pm 1^{\circ} \mathrm{C} .{ }^{15}$ Thickness of tablets was determined using vernier caliper (Mitutoyo Dial Thickness Gauge, Mitutoyo, Japan). Wetting time was recorded by taking $10 \mathrm{ml}$ of phosphate buffer pH 6.8 in petridish, over this fourfold tissue paper was placed and a tablet was carefully placed over this. Time required for a tablet to wet was recorded as wetting time. For determination of drug content ten tablets from each formulation batch was taken randomly and triturated to fine powder. Weight of powder equivalent to $150 \mathrm{mg}$ was taken in phosphate buffer $\mathrm{pH} 6.8$ and assayed for drug content uniformity using double beam UV -visible spectrophotometer at $\lambda_{\max } 325 \mathrm{~nm}$. 


\section{In vitro drug dissolution study}

In vitro release of the drug was evaluated by Lab India Dissolution Apparatus (LABINDIA DS 80 oo, India), using phosphate buffer of $\mathrm{pH} 6.8$ as the dissolution media (900 ml) which was maintained at a temperature of $37 \pm 1^{\circ} \mathrm{C}$ for half an hour, at $75 \mathrm{rpm}$. After specified time interval, $5 \mathrm{ml}$ of sample was withdrawn and concurrently replaced with the same volume of dissolution media. Spectrophotometrical analysis of the samples were measured at a wavelength of $250 \mathrm{~nm}$, and \% cumulative drug release was calculated. ${ }^{16}$

\section{Drug release kinetics}

Mechanism of drug release and kinetic followed was studied by fitting the data of drug release in different kinetic models i.e. zero order, first order, Higuchi, Hixson-Crowell and Korsmeyer- Peppas model. ${ }^{17,18}$

\section{Zero order equation:}

$\mathrm{Q}_{\mathrm{t}}=\mathrm{K}_{\mathrm{o}} \mathrm{t}$

$Q_{t}=$ percentage of drug release in time $t$

$\mathrm{K}_{\mathrm{o}}=$ release rate constant.

\section{First order equation:}

In $\left(100-Q_{t}\right)=\operatorname{In} 100-K_{1} t$

$\mathrm{K}_{1}=$ release rate constant

\section{Higuchi's equation:}

$\mathrm{Q}_{\mathrm{t}}=\mathrm{k}_{\mathrm{H}} \mathrm{t}^{1 / 2}$

$\mathrm{k}_{\mathrm{H}}=$ Higuchi constant

\section{Hixson Crowell:}

$(100-Q t)^{1 / 3}=100^{1 / 3}-k_{\mathrm{HC}} t$

$\mathrm{k}_{\mathrm{HC}}=$ Hixson Crowell constant

\section{Korsmeyer- Peppas:}

$Q_{\mathrm{t}} / \mathrm{Q}_{\mathrm{n}}=\mathrm{k}_{\mathrm{Hp}} \mathrm{t}^{\mathrm{n}}$

$Q_{t} / Q_{n}=$ fraction of drug release in time $t$

$\mathrm{n}=$ release exponent

$\mathrm{k}_{\mathrm{Hp}=}$ constant. 


\section{Stability studies}

Stability testing of F3 formulation selected on the basis of release studies was carried out as per the ICH stability testing guidelines at $40^{\circ} \mathrm{C}$ with $75 \%$ relative humidity, tablet samples were loaded in stability test chamber (Remi Instruments, India) and samples were withdrawn at different time points 15, 30, 45, 60 and 90 days. ${ }^{19}$ Samples were evaluated for disintegration time, in vitro drug release and uniformity in content.

\section{RESULTS AND DISCUSSION}

\section{Physicochemical evaluation of mucilage}

Mucilage from the seeds of Salvia hispanica was isolated with the help of standard procedure. The total yield of mucilage obtained was $12 \%$. The isolated mucilage was greyish white in colour and mucilaginous in taste. The physicochemical properties of isolated mucilage were analyzed and the results are listed in Table 2.

Table 2. Physicochemical evaluation of Salvia hispanica mucilage.

\begin{tabular}{|c|l|l|}
\hline S.No & Properties evaluated & Observations \\
\hline $\mathbf{1}$ & Colour & Greyish white \\
\hline $\mathbf{2}$ & Taste & Mucilaginous \\
\hline $\mathbf{3}$ & Odour & Odourless \\
\hline $\mathbf{4 .}$ & Appearance & Flaky appearance \\
\hline $\mathbf{4}$ & Solubility & Forms viscous solution in water \\
\hline $\mathbf{5 .}$ & pH (By Digital pH meter) & $6.4^{\star}$ \\
\hline $\mathbf{6 .}$ & Swelling ratio & $9^{\star}$ \\
\hline $\mathbf{7 .}$ & Viscosity (1\% solution) & $416 \mathrm{cps}$ \\
\hline $\mathbf{8 .}$ & Test for Carbohydrates (Molisch's test) & +ve \\
\hline $\mathbf{9 .}$ & Test for Tannins (Ferric chloride test) & -ve \\
\hline $\mathbf{1 0 .}$ & Test for proteins (Ninhydrin test) & -ve \\
\hline $\mathbf{1 1 .}$ & Test for alkaloids (Wagner's test) & -ve \\
\hline $\mathbf{1 2 .}$ & Test for glycosides & +ve \\
\hline $\mathbf{1 3 .}$ & Test for mucilage (Ruthenium red test) & +ve \\
\hline $\mathbf{1 4 .}$ & Test for reducing sugar (Fehling's test) & +ve \\
\hline $\mathbf{1 5 .}$ & Mounting with lodine Solution & +ve \\
\hline $\mathbf{1 6 .}$ & Test for uronic acid & + ve \\
\hline & & \\
\hline
\end{tabular}

${ }^{*}$ Results are expressed as mean $(\mathrm{n}=3),+\mathrm{ve}=$ Positive, $-\mathrm{ve}=$ Negative 


\section{Standard calibration curve of Indomethacin}

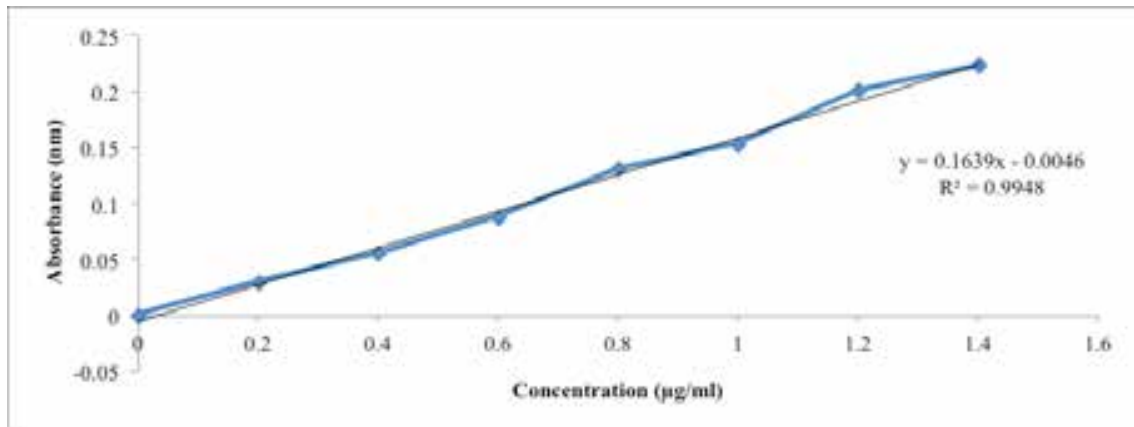

Figure 1. Standard calibration curve of Indomethacin.

Figure 1 shows the standard calibration curve of Indomethacin by plotting the absorbance on $y$-axis and concentration on $x$-axis of the graph. The correlation coefficient determined by the standard calibration curve was found to be 0.994 .

\section{Drug-excipients compatibility study}

FTIR spectra of indomethacin, Salvia hispanica mucilage and mixture of drug and mucilage are given in Figure 2. Spectral analysis indicated all the important peaks of drug in the FTIR of drug and mucilage mixture which indicates that indomethacin is functionally compatible with the mucilage.

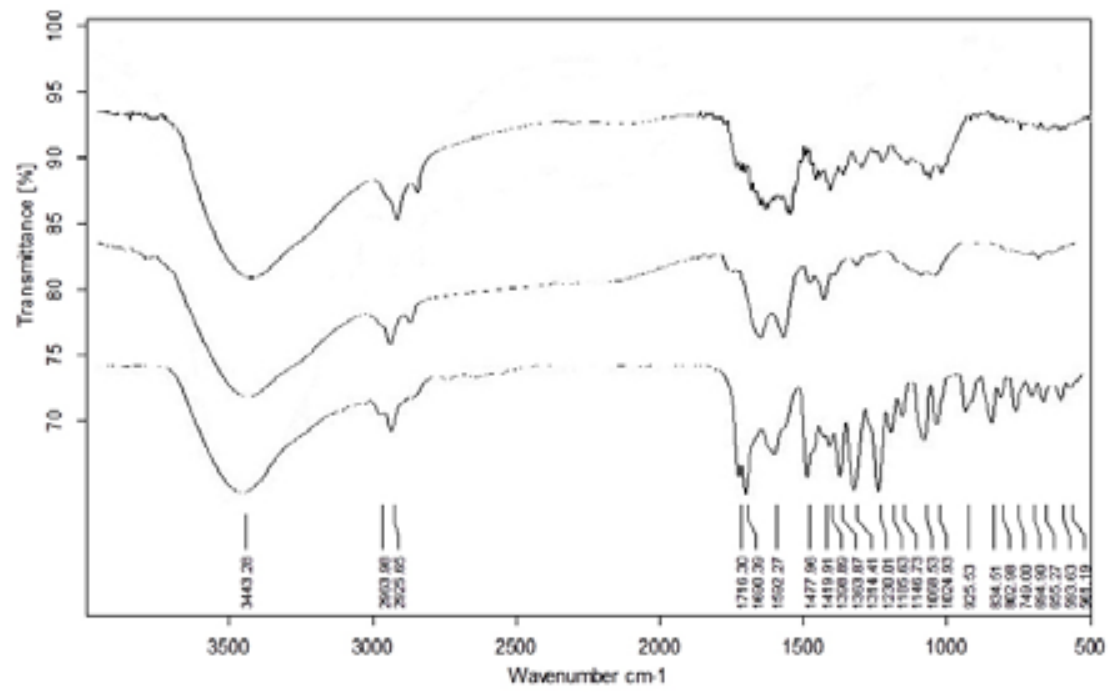

Figure 2. FTIR Spectra of a) Indomethacin b) Salvia hispanica mucilage c) Indomethacin+ Salvia hispanica mucilage. 


\section{Pre-compression parameter}

Six formulation batches of indomethacin tablets (F1-F6) were formulated, each having different concentration of mucilage. The flow properties of different powder blends were analyzed by angle of repose, Carr's index and hausner ratio. The angle of repose values lie within the range $28.65-21.6$, which indicates excellent flow ability. Carr's index between $19-11 \%$ and hausner ratio values ranging between 1.29-1.21 shows good flow characteristics. Table 3 depicts the outcome of pre compression parameters of formulation blends (F1-F6).

Table 3. Evaluation of precompression parameters of formulation blends of Indomethacin tablets.

\begin{tabular}{|l|c|c|c|c|c|c|}
\hline Parameters & F1 & F2 & F3 & F4 & F5 & F6 \\
\hline $\begin{array}{l}\text { Bulk Density } \\
\left(\mathbf{g} / \mathbf{~ c m}^{3}\right)^{*}\end{array}$ & $0.036 \pm 0.06$ & $0.034 \pm 0.01$ & $0.032 \pm 0.02$ & $0.031 \pm 0.01$ & $0.031 \pm 0.02$ & $0.034 \pm 0.01$ \\
\hline $\begin{array}{l}\text { Tapped Density } \\
\left(\mathbf{g} / \mathbf{c m}^{3}\right)^{*}\end{array}$ & $0.048 \pm 0.5$ & $0.052 \pm 0.07$ & $0.054 \pm 0.05$ & $0.05 \pm 0.05$ & $0.05 \pm 0.02$ & $0.054 \pm 0.03$ \\
\hline Angle of Repose & $25.7 \pm 0.51$ & $28.65 \pm 0.03$ & $23.9 \pm 0.1$ & $27.9 \pm 0.2$ & $27.7 \pm 0.1$ & $21.6 \pm 0.01$ \\
\hline Carr's Index & $19 \%$ & $13 \%$ & $11 \%$ & $18 \%$ & $18 \%$ & $17 \%$ \\
\hline Hausner's Ratio & 1.21 & 1.24 & 1.25 & 1.26 & 1.27 & 1.29 \\
\hline
\end{tabular}

${ }^{*}$ mean $\pm \mathrm{SD}, \mathrm{n}=3$

\section{Post compression parameter}

The hardness value of all the tablets was in the range of $1.5-2.5 \mathrm{~kg} / \mathrm{cm}^{2}$. The friability test was done to examine the durability and depict how much mechanical stress the tablets can withstand during their manufacturing, distribution and handling by the customer. According to IP, the percent friability value should not exceed above $1 \%$. All the prepared tablet formulations show values between $0.3-0.75$ percent, which means the friability test, was passed by all of them as per the standard value. The disintegration time has a range of 19-72 sec and it decreased with an increase in concentration of mucilage. Table 4 depicts the results for all the evaluation parameters. 
Table 4. Evaluation of post compression parameters of Indomethacin fast dissolving tablet.

\begin{tabular}{|l|c|c|c|c|c|c|}
\hline Formulation & F1 & F2 & F3 & F4 & F5 & F6 \\
\hline $\begin{array}{l}\text { Hardness } \\
\text { (kg/cm²) }^{\mathrm{a}}\end{array}$ & $4.2 \pm 0.05$ & $3.8 \pm 0.01$ & $3.2 \pm 0.02$ & $3.6 \pm 0.03$ & $3.5 \pm 0.04$ & $3.5 \pm 0.02$ \\
\hline \% Friability & 0.74 & 0.23 & 0.5 & 0.4 & 0.4 & 0.32 \\
\hline $\begin{array}{l}\text { Disintegration } \\
\text { Time(sec) }\end{array}$ & $71.6 \pm 0.01$ & $61.3 \pm 0.03$ & $25.2 \pm 0.03$ & $49.6 \pm 0.04$ & $52.6 \pm 0.06$ & $21.2 \pm 0.03$ \\
\hline Thickness (mm) & $5.5 \pm 0.13$ & $5.3 \pm 0.15$ & $5.2 \pm 0.02$ & $5.5 \pm 0.08$ & $5.1 \pm 0.21$ & $5.3 \pm 0.02$ \\
\hline $\begin{array}{l}\text { Wetting time } \\
\text { (sec) }\end{array}$ & $52.3 \pm 0.03$ & $42.3 \pm 0.04$ & $14.05 \pm 0.02$ & $32.23 \pm 0.03$ & $30.05 \pm 0.11$ & $18.92 \pm 0.12$ \\
\hline Drug content ${ }^{\mathrm{a}}$ & $98.2 \pm 0.23$ & $99.3 \pm 0.24$ & $99.5 \pm 0.01$ & $98.5 \pm 0.08$ & $98.2 \pm 0.25$ & $99.3 \pm 0.06$ \\
\hline
\end{tabular}

${ }^{\text {a }}$ mean $\pm \mathrm{SD}, \mathrm{n}=3$

\section{Drug release}

In vitro drug release study is shown in Figure 3. The formulation $\mathrm{F}_{3}$ containing $6 \%$ of Salvia hispanica mucilage exhibit maximum drug release of $98.5 \%$ in 30 minutes, $\mathrm{F}_{4}$ and $\mathrm{F}_{5}$ formulations containing $8 \%$ and $10 \%$ of Salvia hispanica mucilage showed $82.4 \%$ and $80.5 \%$ drug release in 30 minutes, which indicated that the amount of drug released from the tablets decreased as the concentration of mucilage increased. This can be due to the fact that as the concentration of mucilage increases, it causes an increase in the apparent viscosity. Further, the intermolecular motion of the particles gets restricted and leads to the formation of an interfacial film which slows down the drug release. ${ }^{20}$

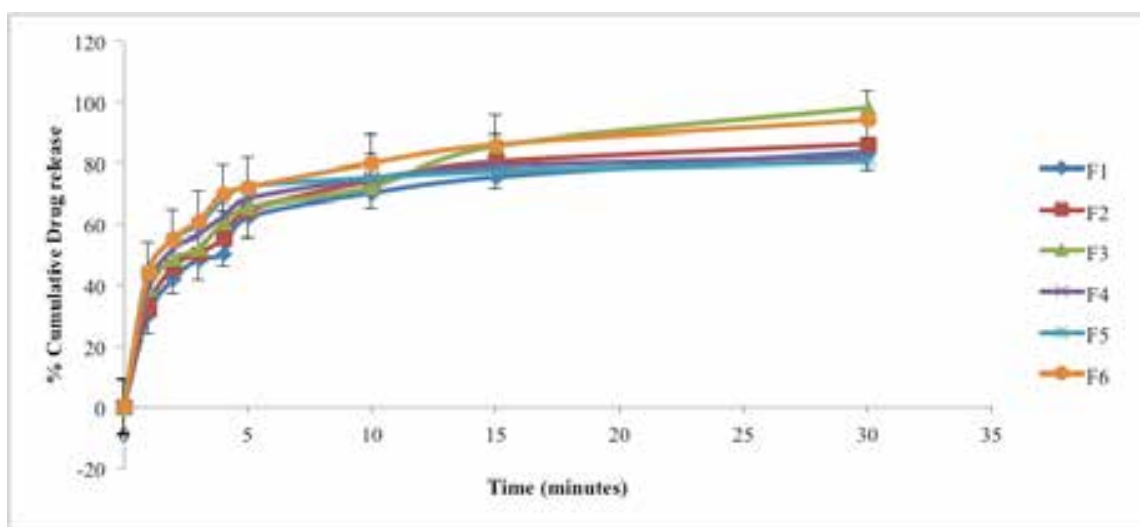

Figure 3. In Vitro drug release plot of F1- F6 formulations. 


\section{Release kinetic study}

Results of in vitro drug released kinetic study as shown in Table 5 indicated that the optimized formulation F3 followed Korsmeyer Peppas model with $\mathrm{R}^{2}$ value of 0.9793 .

Table 5. Release kinetic study of F1-F6 formulations

\begin{tabular}{|c|c|c|c|c|c|}
\hline Formulations & Zero order & First order & Higuchi & \multicolumn{2}{|c|}{ KorsmeyerPeppas } \\
\hline & $\mathbf{R}^{2}$ & $\mathbf{R}^{2}$ & $\mathbf{R}^{2}$ & $\mathbf{N}$ & $\mathbf{R}^{2}$ \\
\hline F1 & 0.743 & 0.8323 & 0.902 & 0.25 & 0.9451 \\
\hline F2 & 0.725 & 0.8268 & 0.896 & 0.24 & 0.9512 \\
\hline F3 & 0.857 & 0.977 & 0.9648 & 0.26 & 0.9793 \\
\hline F4 & 0.639 & 0.673 & 0.8398 & 0.17 & 0.9231 \\
\hline F5 & 0.6177 & 0.6315 & 0.8024 & 0.14 & 0.8745 \\
\hline F6 & 0.7383 & 0.8846 & 0.9103 & 0.19 & 0.9554 \\
\hline
\end{tabular}

\section{Stability studies}

As per the ICH guidelines, stability studies were performed on the promising formulation $\mathrm{F} 3$ under the condition of $40 \pm 2^{\circ} \mathrm{C} / 75 \pm 5 \% \mathrm{RH}$ for 90 days which disclosed that no remarkable variation in the colour, hardness, disintegration time, drug content and in vitro drug release were encountered. This shows the stability of the prepared optimized formulation. Table 6 depicts the corresponding outcomes of the tests performed.

Table 6. Stability studies of F3 formulation at $40 \pm 2^{\circ} \mathrm{C} / 75 \pm 5 \% \mathrm{RH}$.

\begin{tabular}{|l|c|c|c|c|c|}
\hline Parameters & \multicolumn{5}{|c|}{ Days } \\
\hline & $\mathbf{0}$ & $\mathbf{1 5}$ & $\mathbf{3 0}$ & $\mathbf{6 0}$ & $\mathbf{9 0}$ \\
\hline Hardness $\left(\mathbf{k g} / \mathbf{c m}^{2}\right)^{\mathrm{b}}$ & $3.2 \pm 0.02$ & $3.1 \pm 0.1$ & $3.2 \pm 0.07$ & $3.2 \pm 0.05$ & $3.2 \pm 0.02$ \\
\hline $\begin{array}{l}\text { Disintegration Time } \\
(\mathbf{s e c})^{\mathrm{b}}\end{array}$ & $25.2 \pm 0.03$ & $25.2 \pm 0.03$ & $25.2 \pm 0.03$ & $25.2 \pm 0.03$ & $25.2 \pm 0.03$ \\
\hline Drug content ${ }^{\mathrm{b}}$ & $99.5 \pm 0.08$ & $99.0 \pm 0.01$ & $99.2 \pm 0.06$ & $99.2 \pm 0.06$ & $99.5 \pm 0.03$ \\
\hline In vitro release & 98.12 & 98.0 & 98.12 & 98.0 & 98.3 \\
\hline
\end{tabular}

${ }^{b}$ mean $\pm S D, n=3$ 
Salvia hispanica mucilage has a potential to be used as superdisintegrants in place of currently marketed synthetic superdisintegrating agent.

\section{CONFLICTS OF INTEREST}

The authors declare no conflict of interest, financial or otherwise. 


\section{REFERENCES}

1. Sharma, D.; Singh, M.; Kumar, D.; Singh, G. Formulation Development and Evaluation of Fast Disintegrating Tablet of Cetirizine Hydrochloride: A Novel Drug Delivery for Paediatrics and Geriatrics. J. Pharm. (Cairo), 2o14, Article ID 808167, 8 pages.

2. Bhandari, N.; Kumar, A.; Choudhary, A.; Choudhary, R.; Bala, R. A Review on Immediate Release Drug Delivery System. Int. Res. J. Pharm. App. Sci. 2014, 4, 78-87.

3. Desai, P. M.; Liew, C. V.; Heng, P. W. S. Review of Disintegrants and the Disintegration Phenomena. J. Pharm. Sci., 2016, 105, 2545-2555.

4. Markl, D.; Zeitler, J. A. A Review of Disintegration Mechanisms and Measurement Techniques. Pharm. Res., 2017, 34, 890-917.

5. Sharma, D.; Singh, G.; Kumar, D.; Singh, M. Formulation Development and Evaluation of Fast Disintegrating Tablets of Salbutamol Sulphate, Cetirizine Hydrochloride in Combined Pharmaceutical Dosage Form: A New Era in Novel Drug Delivery for Paediatrics and Geriatrics. J. Drug Del., 2015, Article ID 640529, 10 pages

6. Patil, R.; Jagtap, V. A.; Patil, A. V.; Sarode, S. A Review on Role of Novel Superdisintegrants in Pharmacy. Eur. J. Pharm. Med. Res., 2015, 2, 390-400.

7. Bele, M. H.; Derle, D. V. Effect of Sorbed Water on Disintegrant Performance of Four Brands of Polacrilin Potassium NF. AAPS Pharm. Sci. Tech., 2012, 13, 24-34.

8. Kaur, V.; Mehara, M. A Review on: Importance of Superdisintegrants on Immediate Release Tablets.Int. J. Res. Sci., 2016, 3, 39-43.

9. Alam, M. T.; Parvez, N.; Sharma, P. K. FDA-Approved Natural Polymers for Fast Dissolving Tablets. J. Pharm., 2014, Article ID 952970, 6 pages

10. Ullah, R.; Nadeem, M.; Khalique, A.; Imran, M.; Mehmood, S.; Javid, A.; Hussain, J. Nutritional and Therapeutic Perspectives of Chia (Salvia hispanica L.): A review. J. Food Sci. Technol., 2016, 53, 1750-1758.

11. Brutsch, L.; Stringer, F. J.; Kuster, S.; Windhab, E. J.; Fischer, P. Chia Seed Mucilage-A Vegan Thickener: Isolation, Tailoring Viscoelasticity and Rehydration. Food Funct., 2019, 1O, 4854-4860.

12. Madaan, R.; Bala, R.; Vasisht, T.; Sharma, R.; Garg, S. Formulation and Characterization of Matrix Tablets using Mucilage of Tinospora cordifolia as Natural Binder. Int. J. Pharm. Pharm. Sci., 2018, 10, 22-27.

13. Gangwa, S. S.; Tilak, A.; Sharma, R., Verma, M.; Gupta, A. K. Preformulation Studies of Indomethacin Employed for Development of Pharmaceutical Dosage Forms. Int. J. Pharm. Biol. Sci. Arch., 2015, 3, 6-16.

14. Subhashini, R.; Reddy, R. Formulation and Evaluation of Domperidone Fast Dissolving Tablets using Plantago ovata Mucilage. Int. J. Pharm. Sci. Res., 2013, 4, 3489-3493.

15. Indian Pharmacopoeia. Ministry of Health and Family Welfare, Govt. of India, $4^{\text {th }}$ ed.; The Controller of Publication: New Delhi, 1996.

16. Bala, R.; Madaan, R.; Vibhu, A.; Arora, S. Isolation and Evaluation of Hibiscus rosa-sinensis Leaf Mucilage as Superdisintegrant. Eur. J. Pharm. Med. Res., 2016, 3, 434-40.

17. Vargas C. I.; Ghaly E. S. Kinetic Release of Theophylline from Hydrophilic Swell Able Matrices. Drug Dev. Ind. Pharm., 1999, 25, 1045-50. 
18. Korsemeyer, R. W.; Peppas, N. A. Macromolecular and Modelling Aspects of Swelling Controlled Systems. In the Controlled Release Delivery Systems, 1st ed.; Roseman, T. J., Mansdorf, S. Z., Eds.; Marcel Dekker Inc.: New York, 1983; pp 77-80.

19. ICH Harmonised Tripartite Guideline. ICH Topic Q1A (R2). In the Stability Testing of New Drug Substance and Products; European Medicines Agency: London, 2oo3; p 12.

20. Capitani, M.; Corzo-Rios, L. J.; Chel-Guerrero, L.; Betancur-Ancona, D.; Nolasco, S. M.; Tomas, M. Rheological Properties of Aqueous Dispersions of Chia (Salvia hispanica L.) Mucilage. J. Food Eng., 2015, 149, 70-77. 